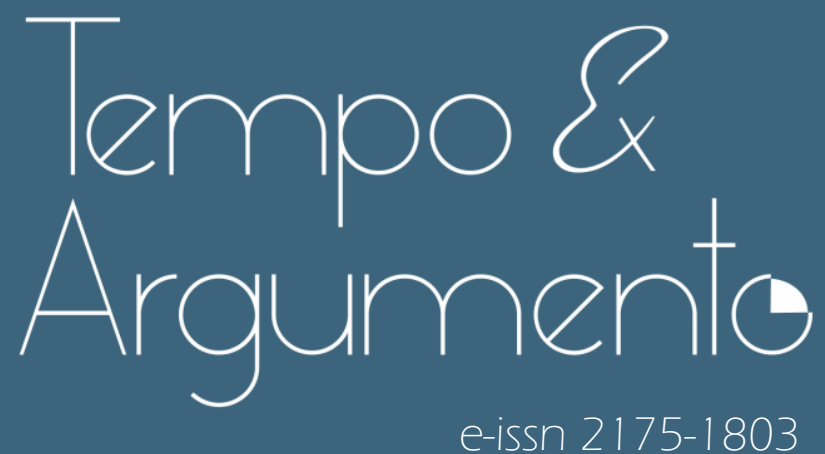

e-issn 2175-1803

\title{
A primavera dos tempos: a retomada das relações franco-brasileiras após a redemocratização brasileira - 1985-1996
}

- Daniel Afonso da Silva

Doutor em História Social pela Universidade de São Paulo (USP).

Estágio Pós-Doutoral no Centre de recherches internationales - Sciences Po.

Pesquisador do Núcleo de Pesquisas em Relações Internacionais (NUPRI/USP).

São Paulo, SP - BRASIL

lattes.cnpq.br/5653749024490442

daniel.afonso66@hotmail.com

(iD)

orcid.org/0000-0002-9785-5894

Para citar este artigo:

SILVA, Daniel Afonso. A primavera dos tempos: a retomada das relações franco-brasileiras após a redemocratização brasileira - 1985-1996. Tempo e Argumento, Florianópolis, v. 12, n. 30, e0203, maio/ago. 2020.

doi http://dx.doi.org/10.5965/2175180312302020e0203 


\title{
A primavera dos tempos: a retomada das relações franco-brasileiras após a redemocratização brasileira - 1985-1996
}

\begin{abstract}
Resumo
A primeira visita de Estado do Presidente Fernando Henrique Cardoso à França do Presidente Jacques Chirac em 28-29 de maio de 1996 consistiu no momento de efetivação da retomada das relações político-diplomáticas franco-brasileiras iniciada com a visita do Presidente eleito Tancredo de Almeida Neves ao Presidente François Miterrand em janeiro de 1985. Este artigo - com base em documentação do Quai d'Orsaye do Élysée na França e do Itamaraty e do Arquivo de Getúlio Vargas no Brasil - procura reconstituir os principais momentos dessa aproximação que foi potencializada pela redemocratização brasileira entre 1985 e 1996.
\end{abstract}

Palavras-chave: Brasil-França. Redemocratização. Fernando Henrique Cardoso. Jacques Chirac. Diplomacia.

\section{The rebirth of history: (the resumption of franco- brazilian relations after the brazilian redemocratization - 1985-1996)}

\begin{abstract}
The first Fernando Henrique Cardoso' presidential visit to the former French President Jacques Chirac on 28-29 May 1996 was the essential moment for the rebirth of the French-Brazilians political-diplomatic relations started from the Tancredo de Almeida Neves visit to the former French President François Mitterrand on January 1985. By sources from Quai d'Orsay and Élysée in France and by Itamaraty and Getúlio Vargas Archives in Brazil, this article tries to show the importance of the Brazilian redemocratization, between 1985 and 1996, in this process of French-Brazilian partnership.
\end{abstract}

Keywords: Brazil-French. Redemocratization. Fernando Henrique Cardoso. Jacques Chirac. Diplomacy. 
Venho a Paris com um objetivo muito claro: o de dar novo vigor ao relacionamento entre o Brasil e a França.

Presidente Fernando Henrique Cardo em jantar oferecido pelo Presidente Jacques Chirac no Palácio do Élysée a 28 de maio de 1996.

Foram muito agradáveis aqueles dias 28 e 29 de maio de 1996 quando o Presidente Fernando Henrique Cardoso promoveu sua primeira visita de Estado à França do Presidente Jacques Chirac. Os jardins em Paris estavam floridos. Vivia-se a primavera. Era março, mês dos recomeços. Mês e estação que serviriam de inspiração ao reatar da relação desses dois Países, Brasil e França, que jamais estiveram totalmente indiferentes um ao outro, mas que desde muito figuravam ausentes em seus compromissos estratégicos comuns (VAÏSSE, 2009). O último grande gesto de interação foi o do General De Gaulle em sua fulgurante visita aos brasileiros em outubro de 1964 (SILVA, 2016). O Marechal Castello Branco retribuiria a viagem do General francês indo a Paris em junho de 1967. O General Costa e Silva faria o mesmo em dezembro do mesmo ano. Mas ambos os brasileiros seriam recebidos sem pompa nem glamour, e a relação francobrasileira seguiriam chafurdando em ostracismos. Os tempos eram difíceis. Dos dois lados do Atlântico. Especialmente pelo conflito Leste-Oeste que monopolizava todas as atenções e preocupações. O Presidente Georges Pompidou manteria uma relação cordata com o General Emílio Garrastazu Médici. Mas jamais viria ao Brasil e a Brasília para vê-lo. Na ocasião da importante exposição da Indústria Francesa em São Paulo, em 1971, por exemplo, enviaria em seu lugar o seu Ministro de Economia e Finanças Valéry Giscard d'Estaing. Quando da eleição do General Ernesto Geisel para a presidência brasileira, o Presidente Pompidou the dirigiria, em março de 1974, uma solene saudação e a indicação de vinda ao Brasil. Mas sua morte no mês seguinte o privaria do propósito. Sob os auspícios do Chanceler brasileiro Azeredo da Silveira, o General Geisel faria uma importante visita de Estado aos franceses em 1976 e receberia, dois anos depois, em 1978, o agora Presidente Valéry Giscard d'Estaing. Mas tudo em discrição e sem maiores efeitos (VAïSSE, 2009, pp. 439-446). Esse momento 
Geisel-Giscard e o marasmo da relação franco-brasileira seriam suplantados somente pelo momentum Tancredo-Mitterrand (SILVA, 2017).

A eleição brasileira de 1985, malgrado indireta e feita no Colégio Eleitoral, elegeu Tancredo de Almeida Neves que, na condição Presidente eleito faria uma grande tournée mundial de apresentação da Nova República. Essa tournée envolveu a França, onde se deu o encontro entre o Presidente Tancredo e Presidente François Mitterrand (RICUPERO, 2010 ; LAFER, 1985). O encontro ocorreu no dia 26 de janeiro daquele ano de 1985 na casa de campo do mandatário francês, em Latche. A interação deles dois causaria forte impressão em ambas as delegações. Imensa sensação de cumplicidade e confiança emergiu daí. A redemocratização brasileira entusiasmava o lado francês e o entourage do Presidente Mitterrand, que logo iniciou a preparação da visita de Estado do Presidente francês ao Brasil ainda para o corrente ano de 1985. Era o início da reaproximação. Ainda discreta, mas verdadeira. A confirmação da democracia brasileira sob as presidências de José Sarney (1985-1990) e Fernando Collor (1990-1992) aceleraria essa interação. Mas seria sob a presidência Fernando Henrique Cardoso (1995-2002) que se daria "novo vigor ao relacionamento entre o Brasil e a França". A recomposição de aspectos desse "novo vigor" na relação franco-brasileira é objeto do que vai a seguir.

\section{Sorvendo lutos}

No início foi o choque.

Desde 10 de fevereiro de 1985, após o momentum Tancredo-Mitterrand, o Chanceler francês Roland Dumas fazia saber às autoridades brasileiras de sua vinda ao Brasil por ocasião da posse do Presidente Tancredo de Almeida Neves representando a França em nome do Presidente François Mitterrand. E indicava que atravessaria o Atlântico com destacados servidores do Quai d'Orsay [Ministério do Exterior] e do Élysée [Palácio Presidencial] - Bernard Dorin, Embaixador da França em Brasília; Alain Boublil, Conselheiro Técnico do Élysée; Robert Richard, Diretor das Américas do Quai d'Orsay, Alain Dejammet, Chefe Do Serviço de Imprensa do Quai d'Orsay, e Pierre-Jean Vandorne, Conselheiro do Ministro - com objetivo de iniciar a renovação efetiva das relações franco- 
A primavera dos tempos: a retomada das relações franco-brasileiras após a redemocratização

brasileiras.' Mas desde o 14-15 de março, tudo se turvou. A internação do Doutor Tancredo de Almeida Neves às vésperas da posse impôs perplexidades em todas as partes, e também de Brasília a Paris (SILVA, 2017).

Desde o início da abertura democrática brasileira que os cenários da realidade brasileira eram auscultados e meditados no Élysée e no Quai d'Orsay. Conselheiros como Régis Debray e enviados nas Américas como Alain Rouquié e o próprio Bernard Dorin eram absolutamente experientes em assuntos latinoamericanos e se especializaram no cotidiano brasileiro. Todos acreditaram - e muitos, inclusive, desejavam - a superação do fardo militar no País. O resultado das eleições de 1985 sugeria alento. Mas o imponderável da doença de Tancredo de Almeida Neves renovou as impressões. O retorno dos militares voltou de súbito aos seus cálculos e temores de brasileiros e franceses. Autoridades francesas de diversos níveis hierárquicos acompanhavam os boletins médicos e a evolução do drama Tancredo com a mesma acuidade dos jornalistas e políticos brasileiros plantados diante do Instituto do Coração em São Paulo. Quando da morte do Presidente brasileiro no dia 21 de abril de 1985, o Presidente Mitterrand, o Maire de Paris, Jacques Chirac, e diversas lideranças políticas não tardaram em enviar os pêsames e as congratulações à família Neves e aos brasileiros nas figuras de suas autoridades. ${ }^{2}$

Depois do choque, o luto.

Com o adeus ao Presidente Tancredo de Almeida Neves, o Vice-Presidente José Sarney sairia da penumbra para assumir os rumos do País. Ele havia participado da situação no regime anterior e, sobretudo por isto, era rejeitado pela opinião pública do após-Diretas Já. Tinha pouco ou nenhum acesso a grupos econômicos apoiadores da candidatura Tancredo de Almeida Neves. Sabia pouco

\footnotetext{
Correspondence 01972 - 1985. Ambassade de France au Brésil. Arquivo do Itamaraty em Brasília. ${ }^{2}$ Correspondence. Jacques Chirac, Maire de Paris. Arquivo do Itamaraty - Embaixada em Paris. Inventário documental I - caixa 4370-81, maço 4373. Telegrama do Presidente François Mitterrand. Arquivo do Itamaraty - Embaixada em Paris. Inventário documental I - caixa 437081, maço 4373. Correspondência. Dona Risoleta Tolentino Neves ao Presidente François Mitterrand. 13 de maio de 1985. Arquivo do Itamaraty - Embaixada em Paris. Troca de notas Embaixada do Brasil e Ministério das Relações Exteriores da França. Janeiro a junho de 1985. Falecimento do Presidente Tancredo de Almeida Neves. Secretaria de estado. 15 de maio de 1985. Arquivo do Itamaraty - Embaixada em Paris. Inventário documental I - caixa 4370-81, maço 4373.
} 
A primavera dos tempos: a retomada das relações franco-brasileiras após a redemocratização brasileira - 1985-1996

do programa de Governo. Havia ingressado na chapa para ser um Vice-Presidente fraco diante de um Presidente forte. Esse era o fato. Mas o destino modificou seus planos. Com a morte de Tancredo ele assumiria a presidência da República e a sua legitimação no poder seria um embate diário. Seu maior desafio era não ser deposto. Fosse por militares ou populares. Todo o resto viria como decorrência (MOISÉS, 1989 ; LEONELLI \& OLIVEIRA, 2004 ; LYRA, 1999 ; HISTÓRIAS CONTADAS, 2013).

\section{Razões do Brasil}

Malgrado as incertezas brasileiras, o Presidente Mitterrand mantivera sua visita de Estado ao Brasil, agendada para outubro de 1985. ${ }^{3}$ Havia semanas que Quai d'Orsay e Itamaraty preparavam os detalhes da visita e, sobretudo, do encontro entre os chanceles, Olavo Setubal pelo Brasil e Ronald Dumas pela França. No dia 8 de outubro se confirmou o local e horário do encontro deles. Seria no Gabinete do Chanceler brasileiro, às 17h40.4 O núcleo da discussão seria o projeto Brasil-França de autoria brasileira. Esse projeto havia sido despachado com antecedência às autoridades francesas desde o Gabinete do Chanceler Setúbal. O projeto Brasil-França envolvia dois eixos de ação. O primeiro consistia na consolidação dos programas de intercâmbio franco-brasileiros existentes. 0 outro sugeria a promoção de um conjunto de eventos para realçar a reciprocidade e o reconhecimento mútuo entre os Países. Esses eventos incorporariam atividades e discussões no âmbito de cultura, educação, esporte, cooperação científica e industrial em níveis nacionais, estaduais e municipais tendo por meta a) fazer convergir os elementos de união franco-brasileira, b) renovar o conhecimento das potencialidades atuais dos Países e c) refletir em conjunto sobre os grandes problemas do mundo. ${ }^{5}$

O evento fundador dessa parceria ocorreria no Olympia, em Paris, em 1986, com espetáculos musicais de eminentes músicos brasileiros como Baden Powell,

\footnotetext{
${ }^{3}$ Correspondence 18527 - 1985. Ambassade de France au Brésil. Arquivo do Itamaraty em Brasília.

${ }^{4}$ Correspondence. 8 octobre 1985. Ambassade de France au Brésil. Arquivo do Itamaraty em Brasília.

${ }^{5}$ Brasil-França. Troca de cartas a respeito do projeto Brasil-França. Ostensivo - despachos 1985. Arquivo do Itamaraty em Brasília.
} 
Maria Bethânia, Chico Buarque, Milton Nascimento, Gilberto Gil, Paulinho da Viola, Djavan, Gal Costa, Paulo Moura, Fafá de Belém, Moraes Moreira, Luiz Gonzaga e Alceu Valença. 1987 seria marcado pelo ciclo Le Cinéma Brésilien no Centro Georges Pompidou, pela exposição de 350 peças de arte popular brasileira no Grand Palais, pelo colóquio Imagens Recíprocas do Brasil e da França orientado por Celso Furtado, pelos concertos comemorativos do centenário de Heitor VillaLobos, pela mostra Jean Baptiste Debret - um pintor filósofo no Brasil, pela exposição de Cícero Dias na Galeria Denise René e pela presença massiva de escritores brasileiros - Jorge Amado, Antonio Callado, Zélia Gattai, Ferreira Gullar, José Guilherme Mérquior, Josué Montello, Raduan Nasssar, Antonio Olinto, Nélida Piñon, Affonso Romano de Sant’Anna, José Rubem Fonseca, Napoleão Sabóia, Herberto Salles, Silviano Santiago, Lygia Fagundes Telles, Antonio Torres, João Ubaldo Ribeiro e Edla Van Steen - no Salão do Livro. 1988 contaria com a mostra Modernidade - Art Brésilienne du 20ème siècle de curadoria de Aracy Amaral, Marie-Odile Briot, Frederico Morais e Roberto Pontual no Museu de Arte Moderna da Cidade de Paris e com a fundação da Cátedra de História do Brasil na Sorbonne sob a direção de Kátia de Queirós Mattoso. 1989 contaria com a inauguração da exposição O Arquiteto e a Floresta de Zanine Caldas no Musée des Arts Décoratifs e com a restauração do edifício projetado por Grandjean de Montigny, na Praça do Comércio do Rio de Janeiro, para a instalação da Casa França-Brasil. ${ }^{6}$

O envolvimento político, diplomático e burocrático forjado por esse projeto Brasil-França permitiria a franca reaproximação dos dois Países em profundas transformações naqueles fins dos anos de 1980. Doravante, franceses e brasileiros, em cargos públicos ou profissões liberais, passaram a se frequentar correntemente em missões públicas ou privadas oficiais sem nenhum constrangimento. O luto dos brasileiros acabou em muito diluído no entusiasmo da Constituição de 1988 e das eleições presidenciais do ano seguinte. Esses feitos concorreram para contagiar os franceses a interagir mais e melhor com o Brasil.

O Governador do Distrito Federal, José Aparecido de Oliveira, por exemplo, seria recebido em audiência privada pelo Presidente Mitterrand, a 6 de maio de 
A primavera dos tempos: a retomada das relações franco-brasileiras após a redemocratização brasileira - 1985-1996

1987, para se discutir estudo para a confecção de metrô de Brasília. ${ }^{7}$ O Presidente José Sarney passou a ter a liberdade de enviar romances, e muito especialmente o Au-delà du fleuve traduzido em 1988 e publicado pela editora Stock do grupo Hachette, a autoridades francesas. ${ }^{8}$ Impulsionado pelo Primeiro-Ministro Michel Rocard, esse e outros livros de brasileiros seriam traduzidos e publicados na França e Jean-Luc Lagardère, Presidente do grupo Matra e do grupo Hachette, seria promovido à condição de representante oficial do Governo francês para estabelecer contatos com escritores e editores brasileiros. ${ }^{9}$ No mesmo segmento, a Press Club France, dirigida por Pascal Savary, seria induzida ao mesmo tipo de interação e enviaria ao Brasil em 1988 o notável Diretor internacional do jornal Le monde, André Fontaine. ${ }^{10}$

No plano mais político, parlamentares franceses foram enviados ao Brasil em 1987, sob a liderança do economista Dominique de Strauss-Khan para avaliar as dívidas brasileiras. Entre 1988 e 1989, muitos parlamentares brasileiros foram recebidos por autoridades francesas. Entre eles, o Doutor Ulysses Guimarães em janeiro de 1989.11

A maior parte dos candidatos às eleições presidenciais brasileiras de 1989 também passariam por Paris. Entre eles, o Deputado Luiz Inácio Lula da Silva acompanhado de Francisco Weffort, Marco Aurélio Garcia, Aluísio Mercadante, Osvaldo Braga e Ricardo Kotscho e o candidato Leonel Brizola com o claro intuito de ser recebido pelo Presidente Mitterrand no Élysée.12 No âmbito dos festejos do Bicentenário da Revolução Francesa, o Presidente brasileiro, José Sarney, seria um dos convidados de honra. No âmbito de discussões sobre questões ambientais e o futuro do planeta, o Professor e Reitor da Universidade de São Paulo José Goldemberg receberia convite de lavra do Presidente francês para participar. ${ }^{13}$

\footnotetext{
7 Rencontre avec l'homme politique Brésilien José Aparecido de Oliveira. 6 mai 1987. Archives Nationales de France, AG/5(4)/CD/206 - dossier 2.

${ }^{8}$ Lettre. Paris, 4 août 1988. Archives Nationales de France, AG/5(4)/CD/206 - dossier 2.

9 Ofício 19545. 24 de setembro de 1990. Ambassade de France au Brésil. Arquivo do Itamaraty. MRE - Divisão de Arquivo. Doc. G54/3/2.

10 Despachos. Paris. 1989. Arquivo do Itamaraty. MRE - Divisão de Arquivo. Doc. G54/3/3.

${ }^{11}$ Despachos. Paris. 1989. Arquivo do Itamaraty. MRE - Divisão de Arquivo. Caixa 35.

12 Despachos. Paris. 1989. Arquivo do Itamaraty. MRE - Divisão de Arquivo. Caixa 35.

13 Despachos. Paris. 1989. Arquivo do Itamaraty. MRE - Divisão de Arquivo. Caixa 35.
} 
Passadas as eleições de 1989, o projeto Brasil-França perdera a impulsão. Franceses e brasileiros já haviam se reconhecido e reaproximado. Necessitavam, doravante, modificar a qualidade da relação. E foi esse o apelo do Presidente eleito Fernando Collor em sua visita de trabalho, antes de sua posse, ao Presidente François Mitterrand em 6 de fevereiro de 1990.14 Mas questões exteriores e interiores ao Brasil e à França dificultariam um salto de qualidade imediato das relações.

\section{Segredos internos}

A lua de mel com a presidência socialista na França durou pouco. Desde o biênio 1983-1984, o Presidente Mitterrand vinha amargando níveis baixíssimos de popularidade. Nas eleições legislativas de 1986 seu partido acabou perdendo a maioria parlamentar. Para manter a governabilidade, foi, então, convocado para Primeiro-Ministro o líder da oposição. Isso ocasionou a primeira coabitação da história política francesa e da presidência Mitterrand. Foi quando o Maire de Paris, Jacques Chirac, que era o Presidente do partido vencedor daquelas eleições legislativas, fora, então, indicado para Primeiro-Ministro (REMOND, 2003).

O histórico de adversidades entre Jacques Chirac e François Mitterrand remonta aos tempos do General De Gaulle. Chirac sempre se posicionara como gaulliste. Mitterrand, embora nem sempre socialista - ele vinha de uma família católica e de direita e até o fim da vida teve dificuldades e se reconhecer como absolutamente socialista -, sempre combatera De Gaulle (WINOCK, 2015). Após a libertação de Paris em 1944 e a instauração da Quarta República francesa, o General francês deixara a vida pública e política para retornar somente em 1958. Nesse período, François Mitterrand servira a vários Governos como Ministro. Quando a crise na Argélia se tornou insustentável pelos banhos de sangue progressivos causados pela guerra civil, o Presidente René Coty convocara o General De Gaulle como o único líder francês capaz de harmonizar o dilema franco-argelino. Mitterrand era contrário a essa ideia e a essa convocação (MALYE, 2010). A cisão política entre a posição do Presidente Coty e o Ministro

\footnotetext{
14 Rencontre avec le Président élu Fernando Collor de Mello. 6 février 1990. Archives Nationales de France, AG/5(4)/CD/206 - dossier 2.
} 
Mitterrand envolvia o debate em torno da Argélia livre e da Argélia francesa. Ou seja, da independência para a Argélia ou da manutenção do mando francês sobre ela. Mitterrand era pela Argélia francesa. Após o retorno do General e seu famoso je vous ai compris, teria início a descolonização paulatina da Argélia (DE GAULLE, 1970). Isso aumentaria a oposição de Mitterrand a De Gaulle, tanto que nas eleições presidenciais diretas de 1965, Mitterrand se oporia ao General nas urnas e levando o herói da France libre ao segundo turno do pleito, o que foi efetivamente percebido como uma semi-humilhação (REMOND, 2003, pp. 633665). Anos antes, em 1964, Mitterrand ainda havia escrito o manifesto antigaulliste sobre o título Coup d'état permanent (MITTERRAND, 1964). E desde então a clivagem de gaulliste e anti-gaulliste vem fortemente marcada na política francesa.

Ao chegar ao poder em 1981, François Mitterrand era, então, o primeiro não-gaulliste e declarado anti-gaulliste a presidir o País durante a Quinta República inaugurada pelo General De Gaulle em 1958. Georges Pompidou e Valéry Giscard d'Estaing, Presidentes franceses após o General, e seus antecessores, eram claramente gaullistes. O incidente de 1986 impusera, portanto, ao Presidente Mitterrand coabitar com gaullistes.

Jacques Chirac havia sido Ministro do General De Gaulle e depois PrimeiroMinistro do Presidente Valéry Giscard d'Estaing. Desde 1976, ele vinha se afirmando como seguidor dos mais legítimos do General. Tanto que faria do RPF - Rassemblement du peuple français [Partido Reunião do Povo Francês] do General De Gaulle em RPR - Rassamblement pour la république [Partido Reunião pela República] com objetivo de realçar os princípios do gaullismo após De Gaulle que saíra da política em 1969 e morrera em 1970. Jacques Chirac disputaria as eleições para a Marie de Paris em 1977. Ganharia. Em seguida disputaria as eleições presidenciais em 1981. Perderia. Nem ao segundo turno chegaria. Mas agora, em 1986, era convocado a Primeiro-Ministro da presidência Mitterrand. Essa situação, a coabitação, causaria, em todos, traumas, choques e tensões (WINOCK, 2015 ; ROUSSEL, 2015 ; SHORT, 2015; GIESBERT, 1996 ; FAVIER \& MARTIN-ROLAND, 1990). 
Entre 1986 e 1988 esse mal-estar político-administrativo certamente modificou as tendências menos estruturais e estruturadas da política externa francesa promovendo, assim, relativo congelamento da interação francobrasileira iniciada com o momento Tancredo-Mitterrand (VÉDRINE, 1996 ; ATTALI, 1993 ; COTTA, 2015). Em 1988, as eleições presidenciais francesas conduziram ao segundo turno o Presidente da República e seu Primeiro-Ministro. François Mitterrand e Jacques Chirac. Mitterrand acabou sendo reconduzido ao cargo para um segundo mandato de sete anos. Chirac retornaria à Marie de Paris. O PrimeiroMinistro da presidência socialista passou a ser Michel Rocard. No entanto, Rocard era oponente do Presidente Mitterrand no interior do Partido Socialista (ROCARD, 2010 ; BARCQUE, 2010). Sua convocação adveio de sua popularidade desde as vésperas das primárias socialistas de 1980. Naquele momento ele era dos mais cotados para concorrer às eleições por sua legenda. François acabou retirandothe a possibilidade e ao ganhar as eleições em 1981 não the conferiu nenhum cargo no Governo. Desde então existia um ressentimento e uma demanda política e popular para seu ingresso no Governo. Isso ocorreria em 1988 (REMOND, 2003).

Mas tensões e constrangimentos seriam abundantes. Especialmente nos domínios exteriores. O avançar das negociações franco-alemãs e francoeuropeias passou a prioridade francesa absoluta desde 1984. A relação atlântica com os Estados Unidos se mantinha em stand by. A inserção francesa na África, Oriente Médio e na Ásia também. A chegada de Gorbachev à presidência da URSS causava apreensão (VAÏSSE, 2009 ; FAVIER \& MARTIN-ROLAND, 1990 ; VÉDRINE, 1996). Sua abertura gradual da política e da economia com sua Perestróica e Glasnost mobilizava as principais chancelarias da Europa. Especialmente a de Paris. Desde os informes de Farewell - funcionário soviético que contrabandeara dados do regime de Moscou aos serviços secretos franceses - a cooperação franco-americana em termos de defesa vinha reforçada (RAYNAUD \& KOSTINE, 2009). Apesar de o Presidente Mitterrand tenha composto seu primeiro Gabinete em 1981 com lideranças comunistas, a presidência Reagan abdicou de suas desconfianças após a partilha francesa dos dados fornecidos pelo Farewell. Paris e Washington - e também Londres - seguiam todos os passos do novo Governo soviético no sentido de forjá-lo à capitulação (NOUZILLE, 2015 ; NOUZILLE, 2012). 
Após a dissolução do bloco soviético, os franceses se depararam com a guerra do Golfo e tomaram partido contra o regime de Saddam Hussein. Em seguida viriam os contenciosos na Bósnia e em Rwanda. Ambos com ampla implicação francesa. Sem contar a guerra civil argelina. Entretanto, o mais decisivo desse período foi certamente a consolidação da Europa com os acordos de Maastricht de 1992 (FONTAINE, 1995 ; VÉDRINE, 1996). No ano seguinte, o Presidente francês perderia novamente a maioria parlamentar e daria início a uma segunda coabitação. Desta vez não com Jacques Chirac, mas com Edouard Balladur.

Sobre diversos aspectos, fora uma cooperação menos agressiva que a de 1986-1988. Mas, a rigor, também redundara em constrangimentos (REMOND, 2003). Mas a variável de importância desse momento talvez tenha sido o agravamento da doença do Presidente.

Desde o início dos anos de 1980 que François Mitterrand fora diagnosticado com câncer de próstata. A moléstia virou segredo de Estado já no início de sua presidência. Mas após operações sucessivas entre 1992 e 1994 o caso passou ao domínio público. Como também viria ao saber de todos a sua colaboração com o regime de Vichy do Marechal Pétain. Essa revelação seria impulsionada pela publicação de Une jeunesse française do jornalista Pierre Péan e causaria imensos constrangimentos ao mandatário francês (PEAN, 1994). Esses constrangimentos seriam acentuados pela revelação pública da existência de sua segunda família com Anne Pingeot e de sua filha Mazarine Pingeot. Tudo isso tornou o fim da presidência Mitterrand relativamente escandaloso (SHORT, 2015).

Do lado brasileiro, a matriz de escândalos e dos constrangimentos advinha das revelações de Pedro Collor de Mello sobre as incontinências do tesoureiro da campanha de seu irmão e agora Presidente Fernando Collor de Mello. O impeachment do primeiro Presidente eleito por votação direta após tanto tempo deixou avariada a confiabilidade exterior brasileira desde a França. Mesmo se a Constituição de 1988 e as eleições presidenciais de 1989 tenham causado as melhores impressões.

O segundo turno entre o metalúrgico do ABC paulista e o Governador das Alagoas gerou diversas expectativas entre brasileiros e estrangeiros. Como Presidente eleito, Fernando Collor de Mello fizera o tour du monde para 
apresentar o Brasil novo em inícios de 1990. Grande entusiasmo recobria o Brasil e o mundo com relação ao Brasil. O "caçador de marajás" parecia realmente competente para dar cabo aos problemas brasileiros, sendo a inflação entendida como o pior deles. O povo estava com ele, o novo Presidente. Tanto que o elegera no pleito anterior. Mas os parlamentares, não. Sua posse fora melancólica. Seu estilo presidencial, considerado despido de decoro. Sua juventude - ele vinha de completar 40 anos - era sinônimo de inexperiência aos homens do Congresso em grande parte carcomidos pelo tempo. Seu relacionamento com os media, especialmente com a televisão, era entendido como expressão de vulgaridade e hiperexposição. Seu apoio majoritário advinha das urnas. Seus críticos, de todas as partes. Seu plano de contenção da liquidez com o congelamento das poupanças causou imenso desgaste político. Mas, mesmo em ruínas, ele conseguiria projetar maior participação do País na competição internacional. Ou mais diretamente o início da inserção do Brasil nas rotas da globalização. Teria sucesso na recepção da reunião das Nações Unidas sobre o Clima - a Rio 92 ou Eco 92. E também faria avançar as negociações da criação do Mercosul. Mas seus segredos internos divulgados por seu irmão Pedro Collor deixaram dificultada a manutenção de sua presidência. As investigações sobre os atos de corrupção praticados por seu tesoureiro de campanha que agora era indiciado por promover tráfico de influência a partir de seus contatos no poder levaram a opinião pública brasileira a se opor ao Presidente. Muitos brasileiros passaram a portar vestes pretas - símbolo de luto - em lugar de atender ao pedido do Presidente para que portassem o verde e amarelo, cores da bandeira nacional. O País parecia em féretro. Os jovens pintavam o rosto e iam às ruas pedindo a saída do Presidente. Ele atenderia. Renunciaria. Mas seu impeachment também seria aprovado. Assumiria a presidência brasileira novamente um vice-Presidente. Desta vez o baiano-mineiro Itamar Franco (VELHO, 1990 ; OLIVEIRA, 1992 ; WEYLAND, 1993 ; SALLUM JR., 2011a e 2011b ; ROSA E SILVA, 1993 ; PAIXÃO E CASARÕES, 2012 ; MOISÉS, 1989a ; COLLOR DE MELLO, 2007 ; CONTI, 2012).

\section{Entre amigos}

A despeito dessas contingências, França e Brasil continuaram sua interação. 
A primavera dos tempos: a retomada das relações franco-brasileiras após a redemocratização brasileira - 1985-1996

Após tomar partido na guerra do Golfo, o Presidente François Mitterrand enviaria ao Brasil sua emissária Edwige Avice para apresentar as razões francesas e solicitar apoio brasileiro. Dizia o comunicado que

"a França segue amplamente convicta de que o Brasil, por seu lugar no seio da comunidade internacional, deve possuir um papel importante na implantação de dispositivos para ajudar a por fim a uma situação que representa uma grave violação de princípios que regem as relações entre Estados". ${ }^{15}$

Verdade que a enviada francesa tinha por missão visitar as principais capitais sulamericanas com o mesmo objetivo e que o Presidente Mitterrand havia enviado emissários no mesmo interesse às mais variadas partes do mundo. Entretanto, em anos anteriores à redemocratização a possibilidade de atitude similar seria claramente menos verossímil. Da mesma maneira, a visita de uma semana de Jean-Luc Lagardère.

Embora enviado como Presidente dos grupos Matra e Hachette, nesses inícios dos anos de 1990, Lagardère era dos mais importantes empresários franceses na área aeronáutica e de tecnologia militar. Ele vinha ao Brasil para ter encontros com lideranças industriais e financeiras, políticas e econômicas. O Presidente Fernando Collor e a ministra Zélia Cardoso de Mello estavam entre os visitados. Tudo intermediado diretamente pelo Élysée e, portanto, com a chancela do Presidente Mitterrand. ${ }^{16}$

Desde o início de sua presidência, o Presidente francês vinha advogando pela ampliação positiva do multilateralismo internacional com a participação efetiva de Países em vias de desenvolvimento (VAÏSSE, 2009 ; FAVIER, \& MARTINROLAND, 1999 ; VÉDRINE, 1996). A redemocratização dos Países latinoamericanos proporcionou a renovação da presença francesa no continente, com destaque ao Brasil ao sul. O projeto Brasil-França cumpriria sua função e expiraria em 1989.17 Em seguida teria início a gestação de um acordo-quadro que teria suas

\footnotetext{
15 La France est en effet persuadée que le Brésil, par sa place au sein de la Communauté internationale, est applé à jouer un rôle important dans la mise en oeuvre des dispositions arrêtées pour mettre fin à une situation qui constitue une violation grave des principes régissant les relations entre les États". Ofício 17085. 15 de agosto de 1990. Ambassade de France au Brésil. Arquivo do Itamaraty. MRE - Divisão de Arquivo. Doc. G54/3/2.

16 Ofício 19545. 24 de setembro de 1990. Ambassade de France au Brésil. Arquivo do Itamaraty. MRE - Divisão de Arquivo. Doc. G54/3/2.

${ }^{17}$ Despachos. Paris. 1989. Arquivo do Itamaraty. MRE - Divisão de Arquivo. Caixa 35.
} 
A primavera dos tempos: a retomada das relações franco-brasileiras após a redemocratização brasileira - 1985-1996

Daniel Afonso da Silva

linhas gerais apresentadas inicialmente em 1992. Após muitas negociações entre o Itamaraty e o Quai d'Orsay, ele ganharia forma definitiva entre 1995 e 1996 e entraria em vigor após a visita de Estado do Presidente Fernando Henrique Cardoso ao Presidente Jacques Chirac nesses dias 28 e 29 de maio de 1996. Enquanto o Itamaraty e o Quai d'Orsay trabalhavam em silêncio nesse objetivo, os Presidentes Fernando Collor e Itamar Franco seguiam às voltas com a Rodada do Uruguai e não hesitaram em contatar o Presidente francês.

No dia 26 de março de 1991, o Presidente Collor escreveria ao Presidente Mitterrand pedindo a intercessão de seu País no desbloqueio das negociações que se mostravam absolutamente importantes ao Brasil e aos latinoamericanos. ${ }^{18}$ No dia 27 de setembro de 1993, o Presidente Itamar Franco faria o mesmo chamando a atenção para o papel da França no relacionamento com os Países em desenvolvimento. O mandatário brasileiro temia pelo insucesso da rodada. ${ }^{19}$

Nas vésperas das reuniões do G7, os Presidentes brasileiros também se comunicavam com o Presidente francês. Quando do G7 de Tóquio em julho 1993, por exemplo, o Presidente Itamar Franco enviaria uma longuíssima carta ao Presidente Mitterrand chamando atenção para o "singular posicionamento do Brasil" no cenário mundial daquelas alturas. Dizia o mandatário brasileiro que "no atual quadro das relações políticas e econômicas mundiais marcadas por alterações estruturais, julgo necessária uma reavaliação objetiva do perfil do Brasil" e pedia ao seu colega francês que levasse em conta a condição de oitava economia do mundo que era o Brasil, sua tradição de convívio harmonioso no meio internacional, sua necessidade de maior auxílio dos Países do G7 em seu desenvolvimento interno, nas modificações financeiras e econômicas que estavam transformando a inserção internacional do País, em sua liberalização do comércio e crescente privatização. Os números dos intercâmbios comerciais brasileiros acabavam dando razão ao Presidente (vide quadros a seguir)

\footnotetext{
18 Lettre du Président Fernando Collor. 26 mars 1991. Ostensivo - despachos - 1991. Arquivo do Itamaraty em Brasília.

19 Lettre du Président Itamar Franco. 27 septembre 1993. Ostensivo - despachos - 1993. Arquivo do Itamaraty em Brasília.
} 
Quadro 1: Intercâmbio Comercial Brasileiro Geral (em dólares)

\begin{tabular}{|l|c|c|c|c|}
\hline & Exportação (A) & Importação (B) & \multicolumn{2}{|c|}{ Resultados (A-B e A+B) } \\
\hline 1989 & 34.382 .619 .710 & 18.263 .432 .738 & 16.119 .186 .972 & 52.646 .052 .448 \\
\hline 1990 & 31.413 .756 .040 & 20.661 .362 .039 & 10.752 .394 .001 & 52.075 .118 .079 \\
\hline 1991 & 31.620 .439 .443 & 21.040 .470 .792 & 10.579 .968 .651 & 52.660 .910 .235 \\
\hline 1992 & 35.792 .985 .844 & 20.554 .091 .051 & 15.238 .894 .793 & 56.347 .076 .895 \\
\hline 1993 & 38.554 .769 .047 & 25.256 .000 .927 & 13.298 .768 .120 & 63.810 .769 .974 \\
\hline 1994 & 43.545 .148 .862 & 33.078 .690 .132 & 10.466 .458 .730 & 76.623 .838 .994 \\
\hline 1995 & 46.506 .282 .414 & 49.971 .896 .207 & -3.465 .613 .793 & 96.478 .178 .621 \\
\hline 1996 & 47.746 .728 .158 & 53.345 .767 .156 & -5.599 .038 .998 & 101.092 .495 .314 \\
\hline 1997 & 52.982 .725 .829 & 59.747 .227 .088 & -6.764 .501 .259 & 112.729 .952 .917 \\
\hline
\end{tabular}

Fonte: Ministério de Desenvolvimento, Indústria e Comércio Secretaria de Comércio Exterior (MDIC-SECEX)

Quadro 2: Intercâmbio Comercial Geral Brasil-União Europeia (em dólares)

\begin{tabular}{|l|r|r|r|r|}
\hline & \multicolumn{1}{|c|}{ Exportação (A) } & \multicolumn{1}{|c|}{ Importação (B) } & \multicolumn{2}{|c|}{ Resultados (A-B e A+B) } \\
\hline 1989 & 11.530 .200 .546 & 4.290 .994 .180 & 7.239 .206 .366 & 15.821 .194 .726 \\
\hline 1990 & 10.597 .283 .499 & 4.864 .172 .511 & 5.733 .110 .988 & 15.461 .456 .010 \\
\hline 1991 & 10.407 .668 .794 & 5.203 .830 .460 & 5.203 .838 .334 & 15.611 .499 .254 \\
\hline 1992 & 11.032 .475 .494 & 5.060 .118 .232 & 5.972 .357 .262 & 16.092 .593 .726 \\
\hline 1993 & 10.526 .446 .060 & 6.132 .763 .550 & 4.393 .682 .510 & 16.659 .209 .610 \\
\hline 1994 & 12.637 .390 .125 & 9.259 .138 .914 & 3.378 .251 .211 & 21.896 .529 .039 \\
\hline 1995 & 13.395 .099 .573 & 14.307 .429 .229 & -912.329 .656 & 27.702 .528 .802 \\
\hline 1996 & 13.448 .959 .951 & 14.608 .233 .643 & -1.159 .273 .692 & 28.057 .193 .594 \\
\hline 1997 & 15.064 .874 .715 & 16.240 .978 .550 & -1.176 .103 .835 & 31.305 .853 .265 \\
\hline
\end{tabular}

Fonte: MDIC-SECEX

Quadro 3: Intercâmbio Comercial Geral Brasil-França (em dólares)

\begin{tabular}{|c|c|c|c|c|}
\hline & Exportação (A) & Importação (B) & \multicolumn{2}{|c|}{ Resultados (A-B e A+B) } \\
\hline 1989 & 981.628 .498 & 557.685 .323 & 423.943 .175 & 1.539 .313 .821 \\
\hline 1990 & 902.321 .422 & 585.910 .067 & 316.411 .355 & 1.488 .231 .489 \\
\hline 1991 & 864.503 .843 & 632.421 .987 & 232.081 .856 & 1.496 .925 .830 \\
\hline 1992 & 844.255 .074 & 573.173 .798 & 271.081 .276 & 1.417 .428 .872 \\
\hline 1993 & 781.928 .651 & 723.579 .349 & 58.349 .302 & 1.505 .508 .000 \\
\hline 1994 & 900.635 .905 & 863.271 .632 & 37.364 .273 & 1.763 .907 .537 \\
\hline 1995 & 1.038 .389 .092 & 1.382 .488 .842 & -344.099 .750 & 2.420 .877 .934 \\
\hline 1996 & 910.901 .000 & 1.348 .672 .026 & -437.771 .026 & 2.259 .573 .026 \\
\hline 1997 & 1.110 .944 .686 & 1.636 .383 .765 & -525.439 .079 & 2.747 .328 .451 \\
\hline
\end{tabular}

Fonte: MDIC-SECEX 
Pareciam, assim, inconsequentes, ao Presidente brasileiro, as medidas protecionistas e alfandegárias e não-alfandegárias que inibiam a comercialização de produtos brasileiros nos Países que se reuniriam em Tóquio. ${ }^{20}$

Essa "naturalidade" para cobranças advinha claramente do processo de reaproximação entre Brasil e França que vinha se fazendo.

\section{O fazer dos pactos}

Quando o Puligny Montrachet la Garenne Latour 1990 e o Château Haut Brion Graves 1979, vinhos, foram abertos e a orquestra de cordas da presidência da República francesa iniciou pelas 20 h30 seu concerto em homenagem ao Presidente Fernando Henrique Cardoso no jantar de honra que the foi ofertado pelo Presidente Jacques Chirac e sua mulher, Bernadette Chirac, no Élysée, no dia 28 de maio de 1996, a renovação do destino da relação franco-brasileira estava esquadrinhada. Horas antes, o Chanceler brasileiro Luiz Felipe Lampreia havia se encontrado com seu homólogo francês, o Chanceler Hervé Charette, para a assinatura do acordo-quadro entre os dois Países assim como o entendimento de cooperação entre a Agência Espacial Brasileira e o Centro Nacional de Estudos Espaciais da França. Mas o núcleo dessa impulsão remontava ao primeiro de janeiro de 1995, posse do novo Presidente brasileiro.

Após ocupar os cargos de Chanceler e Ministro da fazenda da presidência Itamar Franco, o Senador Fernando Henrique Cardoso, ancorado no sucesso de seu plano de estabilização econômico-financeira do Brasil derrotou seus oponentes no primeiro turno do escrutínio presidencial de 1994. Os brasileiros haviam nele alienado seu destino e os estrangeiros, especialmente os franceses, confiavam nessa aposta.

Dentre os Presidentes civis depois eleitos após a redemocratização brasileira, Fernando Henrique Cardoso era claramente o mais experimentado em assuntos exteriores. Não simplesmente por ter dirigido os negócios externos do

\footnotetext{
${ }^{20}$ Lettre du Président Itamar Franco. 2 juillet 1993. Ostensivo - despachos - 1993. Arquivo do Itamaraty em Brasília.
} 
A primavera dos tempos: a retomada das relações franco-brasileiras após a redemocratização brasileira - 1985-1996

Brasil, mas por sua longa carreira internacional como Professor, sociólogo, exilado e funcionário das Nações Unidas (CARdoso, 2007 ; CARdoso, 2006).

Desde seu Empresário industrial e desenvolvimento econômico no Brasil de 1964, e mesmo antes, ele vinha especulando sobre as dimensões da participação brasileira no sistema capitalista global (CARDOSO, 1964). Quando chegou à presidência, esse fenômeno do sistema atendia por globalização e a tônica de seu discurso ao Congresso Nacional estava assentada sobre fundamentos para a inserção positiva brasileira nessa globalização. ${ }^{21}$ Seu Chanceler Luiz Felipe Lampreia seria o responsável pela implementação desses fundamentos assim como sua tradução ao público.

Em seu discurso de introdução ao cargo de Chanceler proferido no Itamaraty a 2 de janeiro de 1995, Luiz Felipe Lampreia teria sua primeira ocasião de explicitar, portanto, o programa exterior da presidência Fernando Henrique Cardoso. O consenso geral indicava que o Brasil já era um "ator" e um "mercador" global. Mas essa condição não deveria inibir nem tolher a criatividade brasileira frente a globalização. 1995, após a confirmação da estabilidade financeira advinda do Plano Real, era entendido como "um momento de expansão da alma brasileira, em que a confiança do País se renova e o futuro que sempre nos prometemos parece estar mais próximo e seguro". ${ }^{22}$ Esse momento permitiria maior interação positiva do País com a América do Sul via consolidação do Mercosul, com a América do Norte e seu recém-criado NAFTA, com a União Europeia em sua contiguidade e aos mercados da Ásia-Pacífico. ${ }^{23}$ Três meses depois, ele teria ocasião de detalhar os objetivos dessa política externa em sua exposição na Câmara dos Deputados no dia 5 de abril de 1995. Nela o Chanceler Lampreia indicava que em todas essas regiões o essencial seria ampliar a qualidade e a quantidade de parcerias em termos de mercados, tecnologia e investimentos sem perder de vista a busca pela ampliação da participação

\footnotetext{
${ }^{21}$ Discurso no Congresso Nacional a 10 de janeiro de 1995. In: DISCURSOS SELECIONADOS DO PRESIDENTE FERNANDO HENRIQUE CARDOSO. Brasília: Funag, 2009.

22 Discurso pronunciado por sua excelência o Embaixador Luiz Felipe Lampreia por ocasião da cerimônia de transmissão do cargo de Ministro de estado das relações exteriores. Brasília, 2 de janeiro de 1995.

${ }^{23}$ Discurso pronunciado por sua excelência o Embaixador Luiz Felipe Lampreia por ocasião da cerimônia de transmissão do cargo de Ministro de estado das relações exteriores. Brasília, 2 de janeiro de 1995.
} 
A primavera dos tempos: a retomada das relações franco-brasileiras após a redemocratização brasileira - 1985-1996

brasileira em foros decisórios internacionais a partir do redimensionamento da estrutura das Nações Unidas. ${ }^{24}$

Nesse período a França decidia quem seria o sucessor do Presidente François Mitterrand que terminava quatorze anos à frente do País. Jacques Chirac disputava sua terceira eleição presidencial após duas derrotas, 1981 e 1988, para o Presidente Mitterrand. Seu oponente em segundo turno foi o secretário do Partido Socialista Lionel Jospin. Os franceses, cansados de socialistas, acabariam por escolher um seguidor do General De Gaulle (CHIRAC, 2012).

Mesmo que centralizados em sua eleição presidencial, os homens do Quai d'Orsay seguiam os avanços brasileiros. Desde a posse do Presidente Fernando Henrique que os enviados franceses no Brasil e responsáveis pelas Américas em Paris vinham demandando uma visita de Estado do novo mandatário brasileiro à França. Durante todo o mês de janeiro os diplomatas franceses insistiram com o Embaixador brasileiro em Paris, Carlos Alberto Leite Barbosa, para a fixação de uma data. No dia 7 de fevereiro de 1995, o Embaixador Leite Barbosa demandaria ao Chanceler Lampreia a possibilidade de se propor a ida do Presidente brasileiro ao Élysée na segunda quinzena de outubro daquele ano, após sua viagem à Alemanha. Prudente diante do contexto francês, o Chanceler brasileiro recomendaria que se aguardasse o resultado das eleições. ${ }^{25}$

Sagrado, enfim, vencedor no pleito de maio de 1995, o Maire de Paris, Jacques Chirac, indicaria para Primeiro-Ministro Alain Jupé, até então Chanceler francês sob a segunda coabitação da presidência François Mitterrand, e para responsável dos negócios exteriores do País nomearia Hervé Charette (BÉLY et all, 2005). Quando da nomeação de Charette ao Quai d'Orsay, o Chanceler brasileiro the enviaria uma saudação que seria respondida a 8 de junho de 1995 com o claro ensejo de avançar na renovação da relação franco-brasileira. Dizia o Chanceler francês :

\footnotetext{
${ }^{24}$ Apresentação do chanceler Luiz Felipe Lampreia na Câmara dos Deputados a 5 de abril de 1995. Arquivo LFL pi Lampreia, L. F. 1995.04.05. CPDOC-FGV.

25 Telegrama ao Chanceler Luiz Felipe Lampreia. 02/02/1995. Arquivo LFL pi Lampreia, L. F. 1995.04.05. CPDOC-FGV.
} 
A primavera dos tempos: a retomada das relações franco-brasileiras após a redemocratização brasileira - 1985-1996

"sou sabedor da qualidade dos elementos tradicionais que unem - Brasil e a França, mas tenho igualmente consciência dos esforços que nos são necessários para enriquecer esse diálogo. Desejo que nós dois nos apliquemos nesses esforços com determinação nos próximos meses". ${ }^{26}$

No segundo semestre daquele ano de 1995 essa determinação seria posta em marcha e em fins de novembro, o Quai d'Orsay e o Itamaraty conseguiram organizar e confirmar a visita de Estado do Presidente brasileiro à França para fins de maio de 1996. ${ }^{27}$ Para fazer avançar os aspectos concretos da visita para além da simbologia, no dia 13 de dezembro de 1995, desembarcariam em Brasília o Secretário Geral do Quai d'Orsay, Bertrand Dufourcq, e seu subDiretor para as Américas, Patrick Boursin, para passar em revista com seus homólogos brasileiros o Estado da relação franco-brasileira. ${ }^{28}$

O acordo-quadro geral aguardava simplesmente a sua formalização do lado francês. A cooperação judiciária em matéria civil e penal acabava de ser aprovada. Um acordo para permitir o trabalho remunerado dos dependentes dos quadros diplomáticos na França e no Brasil iniciava a sua negociação. O acordo para a prevenção e repressão de infrações aduaneiras ganhava nova discussão. Um acordo sobre a transferência de presos estava em vias de confirmação assim como um acordo para a promoção e proteção recíproca de investimentos. Fazia parte de forte demanda do Itamaraty a isenção de visto para turistas brasileiros na França. O lado francês se ressentia do declínio estrutural da cultura francesa entre os brasileiros, inclusive entre os diplomatas que vinha de ter o francês reduzido em sua importância nos concursos de ingresso à carreira. ${ }^{29}$ Todos esses acordos seriam, enfim, consolidados em fins de maio de 1996, quando da viagem do Presidente brasileiro a Paris.

\footnotetext{
26 "Je sais la qualité traditionnelle des relations qui unissent le Brésil et la France, mais je suis également conscient des efforts qu'il nous faut fournir aujourd'hui pour enrichir ce dialogue. Je souhaite que nous y consacrer tous deux avec détermination dans les mois qui viennent". Telegrama ao Chanceler Luiz Felipe Lampreia. 08/06/1995. Arquivo LFL pi Lampreia, L. F. 1995.04.05. CPDOC-FGV.

${ }^{27}$ MGS - DV 00052Z. 28/11/1995. Secreto. Particular ao Sr. Ministro de Estado. Enviado por Carlos Leite. BRASEMB Paris. Arquivo LFL pi Lampreia, L. F. 1995.04.05. CPDOC-FGV.

28 MGS - OF01288A. 13/12/1995. Confidencial. BRASEMB Paris. Arquivo LFL pi Lampreia, L. F. 1995.04.05. CPDOC-FGV.

29 MGS - OF01288A. 13/12/1995. Confidencial. BRASEMB Paris. Arquivo LFL pi Lampreia, L. F. 1995.04.05. CPDOC-FGV.
} 
A primavera dos tempos: a retomada das relações franco-brasileiras após a redemocratização brasileira - 1985-1996

\section{Paris}

O Presidente Fernando Henrique Cardoso partiria a Paris no domingo, 27 de maio de 1996, em companhia de Dona Ruth Cardoso, do Chanceler Luiz Felipe Lampreia, do Ministro da fazenda Pedro Malan, do Ministro da Cultura Francisco Weffort, do Ministro das Comunicações Sérgio Motta, do Ministro da Administração Luiz Carlos Bresser-Pereira, do Ministro de Ciência e Tecnologia Israel Vargas, da Governadora do Maranhão Roseana Sarney e dos Senadores Antônio Carlos Magalhães (PFL-BA) e Pedro Piva (PSDB-SP).

Os dias 28 e 29 seriam carregados de compromissos na capital francesa. Além de encontros no Élysée com o Presidente Chirac, o Presidente brasileiro seria recebido pelo Presidente da Assembleia Nacional, Philippe Séguin, e pelo Primeiro-Ministro Alain Jupé e daria audiência a Louis Gallois, Presidente da Aérospatiale, Louis Schweitzer, Presidente da Renault Jean Ganois, Presidente do Conselho Nacional do Patronato Francês, Jean Luc-Lagardère, empresários franceses, Jean-Claude Trichet, Presidente do Banco de França. Nos entremeios encontraria momentos para estar com seu fraterno amigo Michel Rocard. Após Paris, ainda iria a Lyon receber o título de Doutor honoris causa no dia 30 de maio. ${ }^{30}$

Àquela altura de 1996, os franceses ainda sentiam a morte de seu Presidente François Mitterrand que ocorrera no 8 de janeiro de 1996. Fora do assédio público ostensivo desde maio de 1995, o mais longevo Presidente da Quinta República francesa foi morrendo em discrição e segredo (SHORT, 2015). Ainda em maio de 1995, o Presidente Fernando Henrique Cardoso the escrevera saudando os seus serviços prestados à França e ao mundo e the convidando a visitar o Brasil ao que ele responderia era sensível à gentileza do convite, no entanto, só seria possível aceitar se as circunstâncias permitissem. ${ }^{31} \mathrm{E}$ elas, as circunstâncias, claramente não permitiram. Mesmo assim, o espírito dos encontros do Presidente brasileiro com autoridades francesas nesses dias 28 e 29 de maio acabaram por atualizar as inspirações do Presidente socialista, que,

\footnotetext{
30 A agenda de FHC na Europa. Folha de S. Paulo, 25/05/1996.

${ }^{31}$ Lettre de François Mitterrand au Président Fernando Henrique Cardoso. BRASEMB Paris. Arquivo LFL pi Lampreia, L. F. 1995.04.05. CPDOC-FGV.
} 
A primavera dos tempos: a retomada das relações franco-brasileiras após a redemocratização brasileira - 1985-1996

Daniel Afonso da Silva

por sua vez, reiterava as premissas da ação exterior francesa instituídas pelo General De Gaulle.

Nos tempos do General De Gaulle o objetivo da política externa francesa era parler à tous para afirmar o País como espécie de troisième force para além do conflito Leste-Oeste (VAÏSSE, 2009 ; VAÏSSE, 1998). Essa estratégia foi materializada no retorno da França a Países asiáticos e latinoamericanos, desde muito ausentes da cartografia exterior francesa (VILLEPIN, 2005). O Presidente François Mitterrand realçaria essa tendência e essa cartografia propondo, inicialmente, pontos de ingresso nos continentes. Para as Américas, o México. Para a África, a Argélia. Para a Ásia, a Índia. Isso para suplantar os pólos Estados Unidos e mundo soviético (BÉLY et all, 2005). Mas essa proposta foi logo substituída pela defesa inapelável dos Países em desenvolvimento através da afirmação de um espaço internacional mais quantitativa e qualitativamente multilateral (VAIISSE, 2009). O Presidente Jacques Chirac atualizaria essas duas tendências para fazer face à hiperpotência norte-americana do após 1989-1991. Em sua exposição das linhas gerais de sua política externa por ocasião da reunião anual dos Embaixadores franceses a 31 de agosto de 1995, ele afirmaria a necessidade de se avançar a consolidação da União Europeia para se concretizar o relacionamento, a partir dela, com os demais blocos, regiões e Países. A regionalização do mundo parecia mais uma tendência, uma realidade. A proposta era afirmar parcerias com Mercosul, ASEAN e o Conselho dos Estados Árabes do Golfo. Mas também sobre os mundos mediterrâneo e africano, asiático e latinoamericano com destaque para China, Índia e Rússia. ${ }^{32}$ O Brasil seria acrescentado após a visita do Presidente brasileiro à França.

Quando da recepção ao Presidente Fernando Henrique Cardoso para o jantar do dia 28 de maio de 1996, o Presidente Chirac enfatizaria a necessidade de aprofundamento das relações francesas com a região latino-americana, pelo Mercosul e pelo Brasil. O Brasil passava a ser não uma porta de acesso à região, mas um parceiro estratégico no corolário das grandes democracias parceiras da França. Daí a necessidade de implicar o Brasil positivamente em discussões globais relacionadas ao meio ambiente, ao terrorismo e às drogas. Mas também

32 Ver CHIRAC, Jacques. Conférence des ambassadeurs. Palais de l'Éysée, 31 août 1995. 
A primavera dos tempos: a retomada das relações franco-brasileiras após a redemocratização

ao destino da globalização/mundialização e das crises que a financeirização decorrente dessa globalização/mundialização vinha causando especialmente nos Países em desenvolvimento. ${ }^{33}$ Do lado do Presidente brasileiro, a manifestação foi no mesmo sentido. O centro de sua preocupação também era os efeitos da globalização, que seria o tema de sua aula proferida em Lyon por ocasião da cerimônia de seu Doutoramento honoris causa dois dias depois. ${ }^{34}$ Mas diante de seu homólogo francês, o Presidente brasileiro acentuaria a força das relações bilaterais franco-brasileiras no domínio cultural, mas que especialmente, doravante, ela não poderia se limitar a isso. Após a longa travessia brasileira sentido à democracia e à estabilização econômico-financeira, o Brasil merecia um tratamento diferenciado de Países como a França. ${ }^{35}$

Esse tratamento diferenciado começou a ser construído no momento Tancredo-Mitterrand. Seria avançado pelo projeto Brasil-França, 1986-1989. Teria seu desenho de concretização afirmado pelo acordo-quadro e pelos demais projetos franco-brasileiros em operação a partir de 1992. E ganharia o sinal verde para a sua efetivação com essa primeira visita do Presidente Fernando Henrique Cardoso ao Presidente Jacques Chirac nessa primavera francesa de 1996 que seria, em verdade, a primavera dos tempos de toda a relação franco-brasileira ulterior.

\footnotetext{
${ }^{33}$ Discours de M. Jacques CHIRAC, Président de la République, à l'occasion du dîner d'état offert en l'honneur de M. Fernando Henrique CARDOSO, Président de la République fédérative du Brésil. Palais de l’Élysée, 28 mai 1996.

34 Conferência na cerimônia de entrega do título de Doutor Honoris Causa pela Universidade Lumière Lyon 2. Lyon, França, 30 de maio de 1996.

35 Discurso no jantar oferecido pelo Presidente da França, Jacques Chirac. Paris, França, 28 de maio de 1996.
} 
A primavera dos tempos: a retomada das relações franco-brasileiras após a redemocratização brasileira - 1985-1996

\section{Fontes primárias}

A agenda de FHC na Europa. Folha de S. Paulo, 25/05/1996.

Apresentação do Chanceler Luiz Felipe Lampreia na Câmara dos Deputados a 5 de abril de 1995. Arquivo LFL pi Lampreia, L. F. 1995.04.05. CPDOC-FGV.

ATTALI, Jacques. Verbatim (I): 1981-1986. Paris : Fayard, 1993.

Brasil-França. Troca de cartas a respeito do projeto Brasil-França. Ostensivo despachos - 1985. Arquivo do Itamaraty em Brasília.

CARDoso, Fernando Henrique. A Arte da política: a história que vivi. Rio de Janeiro: Editora Civilização Brasileira, 2006.

CARdoso, Fernando Henrique. The Accidental President of Brazil: A Memoir. Nova York: PublicAffairs, 2007.

Carta ao Ministro Roland Dumas. 20 de maio de 1985. Arquivo do Itamaraty Embaixada em Paris. Troca de notas - Embaixada do Brasil e Ministério das Relações Exteriores da França. Janeiro a junho de 1985.

CHIRAC, Jacques. Conférence des ambassadeurs. Palais de l'Éysée, 31 août 1995.

CHIRAC, Jacques. Le temps présidentiel. Mémoires. Paris : Nil, 2012.

COLLOR DE MELLO, Fernando Affonso. Relato para a história: a verdade sobre o processo do impeachment. Brasília: Senado Federal, 2007.

Conferência na cerimônia de entrega do título de Doutor Honoris Causa pela Universidade Lumière Lyon 2. Lyon, França, 30 de maio de 1996.

Correspondence 01972 - 1985. Ambassade de France au Brésil. Arquivo do Itamaraty em Brasília.

Correspondence 18527 - 1985. Ambassade de France au Brésil. Arquivo do Itamaraty em Brasília.

Correspondence. 8 octobre 1985. Ambassade de France au Brésil. Arquivo do Itamaraty em Brasília.

Correspondence. Jacques Chirac, Maire de Paris. Arquivo do Itamaraty Embaixada em Paris. Inventário documental I - caixa 4370-81, maço 4373.

Correspondência. Dona Risoleta Tolentino Neves ao Presidente François Mitterrand. 13 de maio de 1985. Arquivo do Itamaraty - Embaixada em Paris.

DE GAULLE, Charles. Discours et messages. Avec le renouveau 1958-1962. Paris : Plon, 1970. 
A primavera dos tempos: a retomada das relações franco-brasileiras após a redemocratização brasileira - 1985-1996

Despachos. Paris. 1989. Arquivo do Itamaraty. MRE - Divisão de Arquivo. Caixa 35.

Despachos. Paris. 1989. Arquivo do Itamaraty. MRE - Divisão de Arquivo. Doc. G54/3/3.

Discours de M. Jacques CHIRAC, Président de la République, à l'occasion du dîner d'état offert en l'honneur de M. Fernando Henrique CARDOSO, Président de la République fédérative du Brésil. Palais de l’Élysée, 28 mai 1996.

Discurso no Congresso Nacional a 10 de janeiro de 1995. In:: DISCURSOS SELECIONADOS DO PRESIDENTE FERNANDO HENRIQUE CARDOSO. Brasília: Funag, 2009.

Discurso no jantar oferecido pelo Presidente da França, Jacques Chirac. Paris, França, 28 de maio de 1996.

Discurso pronunciado por sua excelência o Embaixador Luiz Felipe Lampreia por ocasião da cerimônia de transmissão do cargo de Ministro de Estado das Relações Exteriores. Brasília, 2 de janeiro de 1995.

Discurso pronunciado por sua excelência o senhor Doutor Olavo Setúbal por ocasião da cerimônia de transmissão do cargo de Ministro de Estado das Relações Exteriores. Brasília, 15 de março de 1985.

FONSECA JUNIOR, Gelson. Gelson Fonseca Junior (depoimento, 2008). Rio de Janeiro, CPDOC, 2011.

HISTÓRIAS CONTADAS. Memórias de José Sarney. Brasília: TVSenado, 2013.

Lettre de François Mitterrand au Président Fernando Henrique Cardoso.

BRASEMB Paris. Arquivo LFL pi Lampreia, L. F. 1995.04.05. CPDOC-FGV.

Lettre de Roland Dumas. 14 octobre 1985. Brasil-França. Troca de cartas a respeito do projeto Brasil-França. Ostensivo - despachos - 1985. Arquivo do Itamaraty em Brasília.

Lettre du Président Fernando Collor. 26 mars 1991. Ostensivo - despachos 1991. Arquivo do Itamaraty em Brasília.

Lettre du Président Itamar Franco. 2 juillet 1993. Ostensivo - despachos - 1993. Arquivo do Itamaraty em Brasília.

Lettre du Président Itamar Franco. 27 septembre 1993. Ostensivo - despachos 1993. Arquivo do Itamaraty em Brasília.

Lettre. Paris, 4 août 1988. Archives Nationales de France, AG/5(4)/CD/206 dossier 2. 
A primavera dos tempos: a retomada das relações franco-brasileiras após a redemocratização

MGS - OF01288A. 13/12/1995. Confidencial. BRASEMB Paris. Arquivo LFL pi Lampreia, L. F. 1995.04.05. CPDOC-FGV.

MGS - DV 00052Z. 28/11/1995. Secreto. Particular ao Sr. Ministro de Estado. Enviado por Carlos Leite. BRASEMB Paris. Arquivo LFL pi Lampreia, L. F. 1995.04.05. CPDOC-FGV.

Ministério de Desenvolvimento, Indústria e Comércio - Secretaria de Comércio Exterior (MDIC-SECEX). Brasília, 2000.

MITTERRAND, François. Le Coup d'État permanent. Paris : Plon, 1964.

Ofício 17085. 15 de agosto de 1990. Ambassade de France au Brésil. Arquivo do Itamaraty. MRE - Divisão de Arquivo. Doc. G54/3/2.

Ofício 19545. 24 de setembro de 1990. Ambassade de France au Brésil. Arquivo do Itamaraty. MRE - Divisão de Arquivo. Doc. G54/3/2.

Ofício 19545. 24 de setembro de 1990. Ambassade de France au Brésil. Arquivo do Itamaraty. MRE - Divisão de Arquivo. Doc. G54/3/2.

Rencontre avec l'homme politique Brésilien José Aparecido de Oliveira. 6 mai 1987. Archives Nationales de France, AG/5(4)/CD/206 - dossier 2.

Rencontre avec le Président élu Fernando Collor de Mello. 6 février 1990. Archives Nationales de France, AG/5(4)/CD/206 - dossier 2.

ROCARD, Michel. Si ça vous amuse. Chronique de mes faits et méfaits. Paris: Flammarion, 2010.

ROSA E SILVA, Cláudio Humberto. Mil dias de solidão - Collor bateu e levou. São Paulo: Geração editorial, 1993.

Telegrama ao Chanceler Luiz Felipe Lampreia. 02/02/1995. Arquivo LFL pi Lampreia, L. F. 1995.04.05. CPDOC-FGV.

Telegrama ao Chanceler Luiz Felipe Lampreia. 08/06/1995. Arquivo LFL pi Lampreia, L. F. 1995.04.05. CPDOC-FGV.

Telegrama do Presidente François Mitterrand. Arquivo do Itamaraty Embaixada em Paris. Inventário documental I - caixa 4370-81, maço 4373. Troca de notas - Embaixada do Brasil e Ministério das Relações Exteriores da França. Janeiro a junho de 1985. Falecimento do Presidente Tancredo de Almeida Neves. Secretaria de Estado. 15 de maio de 1985. Arquivo do Itamaraty - Embaixada em Paris. Inventário documental I - caixa 4370-81, maço 4373. 


\section{Referências bibliográficas}

AMARAL, Ruy Pacheco de Azevedo. O Brasil na França. Brasília: Funag, 2008.

BARCQUE, Raphaëlle. L'enfer de Matignon: ce sont eux qui en parlent le mieux. Paris : Points, 2010.

BARRETO, Fernando de Mello. A política externa após a redemocratização. Brasília: Funag, 2012. (Tomo I).

BÉLY, Lucien; SOUTOU, Georges-Henri; THEIS, Laurent; VAÏSSE, Maurice. Dictionnaire des ministres des affaires étrangères. 1589-2004. Paris : Fayard, 2005. pp. 599-618.

CARDOSO, Fernando Henrique. Empresário industrial e desenvolvimento econômico no Brasil. São Paulo: Difel, 1964.

CONTI, Mario Sergio. Notícias do Planalto: a imprensa e o poder nos anos Collor. 2. ed. São Paulo: Companhia das Letras, 2012.

COTTA, Michèlle. Le monde selon Mitterrand. Paris : Tallandier, 2015.

FAVIER, Pierre \& MARTIN-ROLAND, Michel. La décennie Mitterrand. 1 - Les ruptures (1981-1984). 2 - Les épreuves (1984-1988). 3. Les défis. 4. Les déchirements. Paris : Éditions du Seuil, 1990-1999.

FONTAINE, André. Après eux, le Déluge. De Kaboul à Sarajevo - 1979-1995. Paris: Fayard, 1995.

GIESBERT, Franz-Olivier. François Mitterrand, une vie. Paris : Seuil, 1996.

LAFER, Celso. O Legado Diplomático da Viagem Presidencial de Tancredo de Almeida Neves. Contexto Internacional, Rio de Janeiro, vol. 1, n. 2, 1985.

LEONELLI, Domingos \& OLIVEIRA, Dante de. Diretas Já: 15 meses que abalaram a ditadura. Rio de Janeiro: Record, 2004.

LYRA, Fernando. Daquilo que eu sei:Tancredo e a transição democrática. São Paulo: Iluminutas, 1999.

MALYE, François \& STORA, Benjamin. François Mitterrand et la guerre d'Algérie. Paris : Calmann-Lévy, 2010.

MOISÉS, José Alvaro. Dilemas da consolidação democrática no Brasil. Lua Nova, São Paulo, n. 16, pp. 15-86, 1989 a.

MOISÉS, José Álvaro. Eleições, participação e cultura política: mudanças e continuidades. Lua Nova, São Paulo, n. 22, pp. 134-187, 1989b. 
NOUZILLE, Vincent. Les dossiers de la CIA sur la France - 1981-2010: dans le secret des présidents. Nouvelle édition revue et augmentée. Paris: Pluriel, 2012.

NOUZILLE, Vincent. Les tueurs de la république: assassinats et opérations spéciales des services secrets. Paris : Fayard, 2015.

OLIVEIRA, Francisco. Collor: a falsificação da ira. Rio de Janeiro: Imago Editora, 1992.

PAIXÃO E CASARÕES, Guilherme Stolle. O papel do Itamaraty na definição da política externa do Governo Collor de Mello. Revista Brasileira de Política internacional, Brasília, 55 (1): 135-153, 2012.

PEAN, Pierre. Une jeunesse française. François Mitterrand, 1934-1947. Paris : Fayard, 1994.

PINHEIRO, Letícia. Foreign Policy Decision-Making under the Geisel Government: the president, the military and the foreign ministry. Brasilia: Funag, 2013.

RAYNAUD, Eric \& KOSTINE, Sergueï. Adieu Farewell. Paris: Robert Laffont, 2009.

REMOND, René. Histoire de France. Le siècle dernier de 1918 à 2002. Paris: Fayard, 2003.

RICUPERO, Rubens. Diário de bordo - A viagem presidencial de Tancredo. São Paulo: Imprensa Oficial do Estado de São Paulo, 2010.

ROUSSEL, Éric. François Mitterrand. De l'intime au politique. Paris: Robert Laffont, 2015.

SALLUM JR., Brasílio \& PAIXÃO E CASARÕES, Guilherme Stolle. O impeachment do Presidente Collor: a literatura e o processo. Lua nova, São Paulo, 82, pp. 163200, 2011.

SALLUM JR., Brasílio. Governo Collor: o reformismo liberal e a nova orientação da política externa brasileira. Dados - Revista de Ciências Sociais, Rio de Janeiro, vol. 54, n. 2, pp. 259-288, 2011.

SILVA, Daniel Afonso da. A presença do general (ou notícias da visita do presidente Charles de Gaulle ao Brasil em outubro de 1964). Revista Tempo e Argumento, Florianópolis, v. 8, n. 19, p. 307 - 337. set./dez. 2016.

SILVA, Daniel Afonso da. Tancredo-Mitterrand - expresso para Bordeaux. Insight Inteligência, Rio de Janeiro, ano XIX, n.76, p.136-47, jan./fev./março de 2017.

SHORT, Phillip. François Mitterrand. Portrait d'un ambigu. Paris: Nouveau Monde, 2015. 
VAÏSSE, Maurice. La grandeur: la politique étrangère du général de Gaulle (19581969). Paris: Fayard, 1998.

VAÏSSE, Maurice. La puissance ou l'influence? La France dans le monde depuis 1958. Paris: Fayard, 2009. pp. 439-446.

VÉDRINE, Hubert. Les mondes de François Mitterrand. À L'élysée (1981-1995). Paris: Fayard, 1996.

VELHO, Gilberto. A vitória de Collor: uma análise antropológica. Novos Estudos Cebrap, n. 26, pp. 44-47, 1990.

VILLEPIN, Dominique de. Histoire de la diplomatie française. Paris: Perrin, 2005.

WEYLAND, Kurt. The rise and fall of President Collor and its impact on Brazilian Democracy. Journal of interamerican studies and world affairs, vol. 35, n. 1, pp. 137, 1993.

WINOCK, Michel. François Mitterrand. Paris: Gallimard, 2015. 